\title{
Distribution of lactate dehydrogenase in healthy and degenerative canine stifle joint cartilage
}

\author{
Eveline L. C. Walter · David Spreng • Hugo Schmöckel • \\ Peter Schawalder $\cdot$ Peter Tschudi $\cdot$ Armin E. Friess • \\ Michael H. Stoffel
}

Accepted: 16 April 2007 / Published online: 1 June 2007

(C) Springer-Verlag 2007

\begin{abstract}
In dogs, degenerative joint diseases (DJD) have been shown to be associated with increased lactate dehydrogenase (LDH) activity in the synovial fluid. The goal of this study was to examine healthy and degenerative stifle joints in order to clarify the origin of LDH in synovial fluid. In order to assess the distribution of LDH, cartilage samples from healthy and degenerative knee joints were investigated by means of light and transmission electron microscopy in conjunction with immunolabeling and enzyme cytochemistry. Morphological analysis confirmed DJD. All techniques used corroborated the presence of LDH in chondrocytes and in the interterritorial matrix of healthy and degenerative stifle joints. Although enzymatic activity of LDH was clearly demonstrated in the territorial matrix by means of the tetrazolium-formazan reaction, immunolabeling for LDH was missing in this region. With respect to the distribution of LDH in the interterritorial matrix, a striking decrease
\end{abstract}

E. L. C. Walter · A. E. Friess · M. H. Stoffel $(\bowtie)$

Division of Veterinary Anatomy,

Vetsuisse Faculty University of Berne,

POB 3001, Bern, Switzerland

e-mail: michael.stoffel@ita.unibe.ch

D. Spreng · H. Schmöckel · P. Schawalder

Department of Clinical Veterinary Medicine,

Division of Small Animal Surgery,

Vetsuisse Faculty University of Berne,

POB 3001, Bern, Switzerland

P. Tschudi

Department of Clinical Veterinary Medicine,

Central Laboratory Facilities,

Vetsuisse Faculty University of Berne,

POB 3001, Bern, Switzerland from superficial to deeper layers was present in healthy dogs but was missing in affected joints. These results support the contention that LDH in synovial fluid of degenerative joints originates from cartilage. Therefore, we suggest that (1) LDH is transferred from chondrocytes to ECM in both healthy dogs and dogs with degenerative joint disease and that (2) in degenerative joints, LDH is released from chondrocytes and the ECM into synovial fluid through abrasion of cartilage as well as through enhanced diffusion as a result of increased water content and degradation of collagen.

Keywords Dog - Degenerative joint disease . Immunolabeling $\cdot$ Electron microscopy $\cdot$ Enzyme cytochemistry
Abbreviations
AP Alkaline phosphatase
ASAT Aspartate amino transferase
CCB $\quad 0.1 \mathrm{M}$ sodium cacodylate, $2 \mathrm{mM} \mathrm{CaCl}_{2}$, $\mathrm{pH} 7.4$
CCL Cranial cruciate ligament
CFG Cold fish gelatin
DJD Degenerative joint disease(s)
ECM Extracellular matrix
ICC Immunocytochemistry
IHC Immunohistochemistry
LDH Lactate dehydrogenase
NAD Nicotinamide adenine dinucleotide
NBT Nitroblue tetrazolium chloride
NDS Normal donkey serum
SF Synovial fluid
TEM Transmission electron microscopy
TNBT Tetranitroblue tetrazolium chloride 


\section{Introduction}

Degenerative joint disease (DJD) is known as a slowly progressive degenerative condition that gradually leads to complete loss of joint function (Hayashi et al. 2003). This debilitating condition has been reported to affect as many as $20 \%$ of the canine population over 1 year of age (Johnston 1997). The most common cause of canine DJD in stifle joints is the rupture of the cranial cruciate ligament (CCL). This is usually the result of adaptive or degenerative changes within the ligament tissue and, thus, is influenced by age, body weight, and phenotype. Lactate dehydrogenase (LDH) is a ubiquitous cytosolic enzyme that catalyses a critical step in the glycolytic pathway, the reversible conversion of pyruvate to lactate. The enzyme is a tetramer, with either $\mathrm{H}$ or $\mathrm{M}$ subunits or a combination of both. Five different isoenzymes are known to date. In cartilage tissue, LDH4 and LDH5 are the predominant isoforms, as they play a pivotal role in anaerobic metabolic pathways (Yancik et al. 1987). Whereas the diagnosis of arthritis can fall back upon a number of reliable indicators present in synovial fluid (SF), convenient markers for DJD are still lacking in the dog. However, an increase in synovial LDH levels was recently associated with degenerative joint diseases (DJD) (Hurter et al. 2005; Schmöckel et al. 2001). The goal of the present study, therefore, was to elucidate the significant increase of LDH in SF from degenerative joints in the dog. Blood and SF samples were analyzed to monitor the inflammatory status, and articular cartilage from healthy and diseased joints were analyzed morphologically by light and electron microscopy. Furthermore, the presence and activity of LDH were determined by means of immunolabeling and enzyme cytochemistry. We herewith show that the presence of LDH is similar in chondrones of both healthy and degenerative cartilage. However, distribution of LDH within the extracellular matrix (ECM) differs, as the gradient from superficial to deeper layers observed in healthy tissue was lacking in diseased cartilage. These findings suggest that $\mathrm{LDH}$ is released from chondrocytes to ECM in both healthy dogs and dogs with DJD. Whereas, extracellular LDH remains constrained to ECM in sound cartilage, it is lost from damaged cartilage into the synovial fluid through abrasion and enhanced diffusion as a result of increased water content and degradation of collagen.

\section{Materials and methods}

\section{Animals}

Both stifle joints from three male and three female healthy Beagles and from one male Jack Russell Terrier (mean age $6.0 \pm 4.1$ years) were used as controls. These animals were euthanized for reasons not related to joint diseases or inflammatory processes. They had no history of lameness, nor did they show any macroscopic evidence of DJD.

Nine biopsies were from patients with degenerative stifle joints (one female and two neutered female Labrador Retrievers, two neutered female Bernese Mountain Dogs, one neutered male Australian Shepherd dog, one neutered male Boxer, one male English Bulldog, and one neutered female Hovawart, (mean age $5.3 \pm 2.3$ years). These animals had been diagnosed clinically with a rupture of the cranial cruciate ligament. Arthroscopic examination confirmed a partial rupture in five dogs and a total rupture in the remaining four individuals, with all patients showing signs of DJD. None of the dogs had received anti-inflammatory drugs within at least 2 weeks prior to surgery.

\section{Materials and tissue processing}

\section{Synovial fluid}

No SF was collected from control animals. From dogs with DJD, native and EDTA samples of SF were taken prior to surgery. Care was taken to avoid blood contamination. Samples were analyzed for color, clarity, and viscosity and were processed further within 30 min from sample collection. To reduce viscosity for further processing and analysis (Hurter et al. 2005; Schmöckel et al. 2001), SF was digested with hyaluronidase (final concentration of $0.1 \mathrm{mg}$ hyaluronidase/ml, $20 \mathrm{~min}$ at $25^{\circ} \mathrm{C}$ ). Aliquots for total cell counts and differential cell counts (EDTA samples) were removed and concentrated at $72 \times g$ (Cytospin 3, Shandon, Pittsburgh, USA). The remaining synovial fluid was centrifuged at $1,400 \times g$ for $15 \mathrm{~min}$, and total protein content was determined with a Hitachi 912 laboratory analyzer (High Technology Inc, Walpole, USA). Enzymes assessed included LDH, alkaline phosphatase (AP), and aspartate amino transferase (ASAT); their activities were measured at $37^{\circ} \mathrm{C}$ with the Hitachi 912 laboratory analyzer. LDH activity was determined according to Schmöckel et al. (2001).

\section{Blood}

Blood was collected by venipuncture prior to anesthesia both from control animals and from dogs suffering from DJD. Parameters determined included cell count, differential blood count, total protein content, and albumin, lactate, glucose, ASAT (in EDTA sample) and AP (in heparinized blood) concentrations. One aliquot of every sample was centrifuged without delay in order to determine the concentration of LDH in plasma with a Hitachi 912 laboratory 
analyzer (High Technology Inc, Walpole, USA) immediately after blood collection.

\section{Cartilage}

Thin cartilage slices were obtained from control animals immediately after euthanasia. In degenerative stifle joints, cartilage biopsies were collected from the region immediately lateral to the femoral notch during arthroscopy by means of a miniature double-spoon forceps. From dogs with DJD, specimens for morphology, enzyme histochemistry and cytochemistry, and immunolabeling were collected during arthroscopy.

For morphological examination of cartilage samples, $2.5 \%$ glutaraldehyde in CC-buffer (CCB $0.1 \mathrm{M}$ sodium cacodylate, $2 \mathrm{mM} \mathrm{CaCl}$, $\mathrm{pH}$ 7.4) was used as a fixative. Specimens were fixed for $5 \mathrm{~h}$ at room temperature, washed overnight in $\mathrm{CCB}$, and post-fixed for $1 \mathrm{~h}$ with $1 \%$ osmium tetroxide in CCB. After dehydration through an increasing ethanol series, tissue was embedded in either paraffin wax or an Epon/Araldite mixture according to standard protocols. Ultrathin sections $(70 \mathrm{~nm})$ of Epon/Araldite-embedded material were mounted on collodion-coated copper grids and counterstained with uranyl acetate and lead citrate.

Tissue for immunolabeling was fixed with $0.5 \%$ glutaraldehyde, $4 \%$ paraformaldehyde, and $50 \mathrm{mM}$ lysine- $\mathrm{HCl}$ in $0.1 \mathrm{M}$ cacodylate buffer, $\mathrm{pH}$ 7.4. Samples were again fixed for $5 \mathrm{~h}$ at room temperature, dehydrated through an ascending ethanol series, and embedded in LR-White (British Biocell International, Brunschwig, Germany) by thermal curing in an incubator.

Immunohistochemistry and immunocytochemistry

For immunohistochemistry (IHC), semithin sections $(0.5 \mu \mathrm{m})$ of LR White-embedded samples were transferred to glass slides and immunostained as shown in Table 1. A highly purified polyclonal goat anti-rabbit LDH antibody (L1011-09 from US Biological, Swampscott, Massachusetts, USA) that identifys all isoforms was used. After immunogold labeling and subsequent silver enhancement, sections were examined under epipolarization illumination.

For immunocytochemistry (ICC), ultrathin sections $(80 \mathrm{~nm})$ of LR White-embedded material were collected onto collodion-coated 200 mesh nickel grids and immunostained as described in Table 2. Control reactions for IHC and ICC included omission of both primary and secondary antibody, omission of primary antibody, and substitution of primary antibody with either normal goat IgG or goat antihuman choline acetyltransferase (Chemicon International, Inc., Lucerne) as an irrelevant primary antibody.

Enzyme histochemistry and cytochemistry

Enzymatic activity of LDH was assessed by histochemistry and cytochemistry in two healthy dogs and in two dogs with DJD.

Thick sections $(200 \mu \mathrm{m})$ of unfixed joint cartilage were produced with a Vibratome (Oxford Laboratories, Foster City, USA). Incubation was performed with a reaction medium containing $150 \mathrm{mM}$ sodium L-lactate (substrate), $3 \mathrm{mM}$ NAD (co-enzyme), $0.32 \mathrm{mM}$ 1-methoxyphenazine methosulphate, and $5 \mathrm{mM}$ sodium azide in $100 \mathrm{mM}$ phosphate buffer containing $18 \%$ polyvinyl alcohol, $\mathrm{pH} 7.45$ (Van Noorden 1984). Finally, either $4 \mathrm{mg}$ TNBT or $4 \mathrm{mg}$ NBT chloride (Boehringer Mannheim GmbH) were dissolved in $20 \mu \mathrm{l}$ of dimethylformamide and then added as a chromogen to $1 \mathrm{ml}$ of the reaction medium. All chemicals were from SIGMA (Buchs, Switzerland) unless stated otherwise. Tissue slices were incubated for 2 or $3 \mathrm{~h}$ in a dark humid chamber at $37^{\circ} \mathrm{C}$. The viscous incubation medium was rinsed off with warm $100 \mathrm{mM}$ phosphate buffer $(\mathrm{pH}$ 5.3 , approx. $50^{\circ} \mathrm{C}$ ). Thereafter, slices were fixed in $10 \%$ formalin for $10 \mathrm{~min}$, dehydrated in an increasing series of
Table 1 Incubation for immunohistochemistry (light microscopy)
Primary antibody: Goat anti-rabbit lactate dehydrogenase (LDH) antibody (USBiological)

Secondary antibody: $12 \mathrm{~nm}$ colloidal gold-affinipure donkey anti-goat $\mathrm{IgG}(\mathrm{H}+\mathrm{L})$ antibody (Jackson ImmunoResearch)

\begin{tabular}{llll}
\hline Steps & Reagents & Duration & Temperature \\
\hline Blocking step & 5\% NDS, 0.1\% Tween 20, 1.35\% CFG & $30 \mathrm{~min}$ & RT \\
Primary antibody & $\begin{array}{l}\text { Goat anti-rabbit LDH: 1:50 in } \\
\text { blocking solution }\end{array}$ & $5 \mathrm{~h}$ & $\mathrm{RT}$ \\
& Blocking Solution & overnight & $4^{\circ} \mathrm{C}$ \\
Washing step & 5\% NDS, 0.1\% Tween 20 & $2 \times 5 \mathrm{~min}$ & RT \\
& Donkey anti-goat IgG, 12 gold conjugate: & $30 \mathrm{~min}$ & RT \\
Secondary antibody & 1:100 in 5\% NDS, 0.1\% Tween 20 & & \\
& 5\% NDS, 0.1\% Tween 20 & $3 \times 5 \mathrm{~min}$ & RT \\
Washing step & Distilled water & $3 \times 5 \mathrm{~min}$ & RT \\
& Silver kit & $20 \mathrm{~min}$ & RT (in the dark) \\
Silver enhancement & Tap water & $3 \times 5 \mathrm{~min}$ & RT \\
Washing steps & Distilled water & $5 \mathrm{~min}$ & RT \\
& & &
\end{tabular}


Table 2 Incubation for immunocytochemistry (transmission electron microscopy)

\begin{tabular}{|c|c|c|c|}
\hline Steps & Reagents & Duration & Temperature \\
\hline Blocking step & $5 \%$ NDS, $0.1 \%$ Tween $20,1.35 \%$ CFG & $30 \mathrm{~min}$ & RT \\
\hline First antibody & Goat anti-rabbit LDH: 1:50 in blocking solution & $\begin{array}{l}5 \mathrm{~h} \\
\text { overnight }\end{array}$ & $\begin{array}{l}\mathrm{RT} \\
4^{\circ} \mathrm{C}\end{array}$ \\
\hline Washing step & $\begin{array}{l}\text { Blocking solution } \\
5 \% \text { NDS, } 0.1 \% \text { Tween } 20\end{array}$ & $\begin{array}{l}1 \times 5 \min \\
2 \times 5 \text { min }\end{array}$ & $\begin{array}{l}\text { RT } \\
\text { RT }\end{array}$ \\
\hline Second antibody & $\begin{array}{l}\text { Donkey anti-goat } \operatorname{IgG}, 12 \mathrm{~nm} \text { gold conjugate: } \\
1: 100 \text { in } 5 \% \text { NDS, } 0.1 \% \text { Tween } 20\end{array}$ & $90 \min$ & RT \\
\hline Washing step & $\begin{array}{l}5 \% \text { NDS, } 0.1 \% \text { Tween } 20 \\
\text { PBS }\end{array}$ & $\begin{array}{l}2 \times 5 \min \\
4 \times 5 \min \end{array}$ & $\begin{array}{l}\text { RT } \\
\text { RT }\end{array}$ \\
\hline Fixation & $1 \%$ glutaraldehyde in PBS & $10 \mathrm{~min}$ & $\mathrm{RT}$ \\
\hline Washing step & $\begin{array}{l}\text { PBS } \\
\text { Distilled water }\end{array}$ & $\begin{array}{l}3 \times 5 \min \\
3 \times 5 \min \end{array}$ & $\begin{array}{l}\text { RT } \\
\text { RT }\end{array}$ \\
\hline Silver enhancement & Silver kit & $5 \mathrm{~min}$ & RT (in the dark) \\
\hline Washing step & $\begin{array}{l}\text { Tap water } \\
\text { Distilled water }\end{array}$ & $\begin{array}{l}3 \times 5 \min \\
5 \mathrm{~min}\end{array}$ & $\begin{array}{l}\text { RT } \\
\text { RT }\end{array}$ \\
\hline
\end{tabular}

ethanol, and infiltrated and embedded with Unicryl (Polyscience Inc, BBI International, Brunschwig, Germany). In order to enhance tissue contrast for better orientation, a number of sections from one dog were osmicated following a cytochemical reaction. For control reactions, sodium L-lactate and NAD were replaced by distilled water. sections of 5-15 $\mu \mathrm{m}$ were used for light microscopy. For electron microscopic examination, $80 \mathrm{~nm}$ sections were mounted on collodion-coated 200 mesh copper grids.

A Zeiss Axioskop with an AxioCam HR (Feldbach, Switzerland) was used for light microscopic observation, whereas ultrathin sections were examined in a Zeiss transmission electron microscope 109 (Zeiss, Oberkochen, Germany) equipped with a GATAN wide angle slow scan CCD Camera 689 (GATAN GmbH, Munich, Germany).

\section{Results}

Distinction between intact and ruptured CCL in stifle joints was based on clinical examination of cruciate ligaments. Clinical diagnosis was extremely reliable, as arthroscopy and microscopical analysis of cartilage samples fully confirmed the presence of a ruptured CCL and of articular damage in the diseased animals as opposed to healthy dogs.

\section{Morphology}

Light microscopical analysis of specimens included assessment of overall tissue organization, state of cartilage surface, and cell characteristics. Cartilage samples from healthy dogs were smooth-surfaced and displayed the typical stratification (Fig. 1) and cell shapes (Arsenault and Hunziker 1988). Though usually present, the amorphous layer at the articular surface (Fig. 3a, inset) occasionally was discontinuous in healthy dogs. Underneath, the dense network of collagen fibers running in parallel with the articular surface was obvious (Fig. 3a, inset). The territorial and interterritorial ECMs were clearly distinct (Fig. 3b). These features applied to all cartilage strata. Most chondrocytes showed large nuclei and an abundance of organelles (Fig. 3a, b). Intracellular inclusions (Fig. 3a) were noted in all three zones, the largest ones occurring in the radial zone.

In contrast, biopsies from degenerative stifle joints revealed damage to the articular surface, formation of clefts, destruction of the tangential zone, and a disorganization of cartilage layering (Fig. 2a, b). The articular surface was rough and the amorphous layer was completely lacking (Fig. 4) except for some remnants in one single dog. Fibers were arranged at random with extensive amorphous foci between single fibers and fiber bundles (Fig. 4). Characteristic signs of cartilage degeneration, such as hypocellularity and hypercellularity, were obvious. Cell cloning was usually localized to transitional and tangential zones. As compared to healthy cartilage, chondrocytes from degenerative joints were smaller, cell nuclei were often big when present, and depletion of cytoplasmic organelles occurred. Instead, chondrocytes displayed intracellular vacuoles and pericellular blebs. In half the biopsies, small ovoid, amorphous, cell-shaped, translucent structures that contain a network of finer fibrils were observed underneath the surface (Fig. 4).

\section{Immunolabeling}

In healthy $\operatorname{dog} s$, chondrocytes in all three zones were clearly immunopositive for LDH, with the strongest signal observed in the transitional and radial zones (Fig. 5). The 


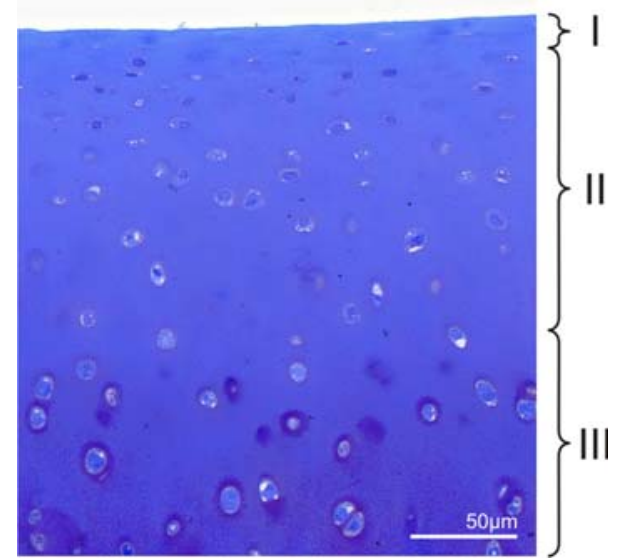

Fig. 1 Light micrograph of a Richardson-stained semithin section of healthy cartilage showing obvious stratification into tangential $(I)$, transitional (II) and radial zones (III). The articular surface is smooth and even

signal was evenly distributed all over the cytoplasm and on mitochondria but was absent from vacuoles. The territorial matrix was basically devoid of labeling (Figs. 5, 8). With respect to the interterritorial ECM, labeling intensity decreased from the tangential zone to the radial zone. However, the amorphous layer and the most superficial layer of collagen fiber displayed a faint signal only (Fig. 6).

In degenerative cartilage (Fig. 6), overall labeling was faint. Chondrocytes in the tangential zone were virtually devoid of any signal, whereas cells in the transitional and radial zones displayed an increasing immunoreactivity. In contrast to healthy cartilage, the gradient in labeling intensity of the ECM was missing except for those areas where

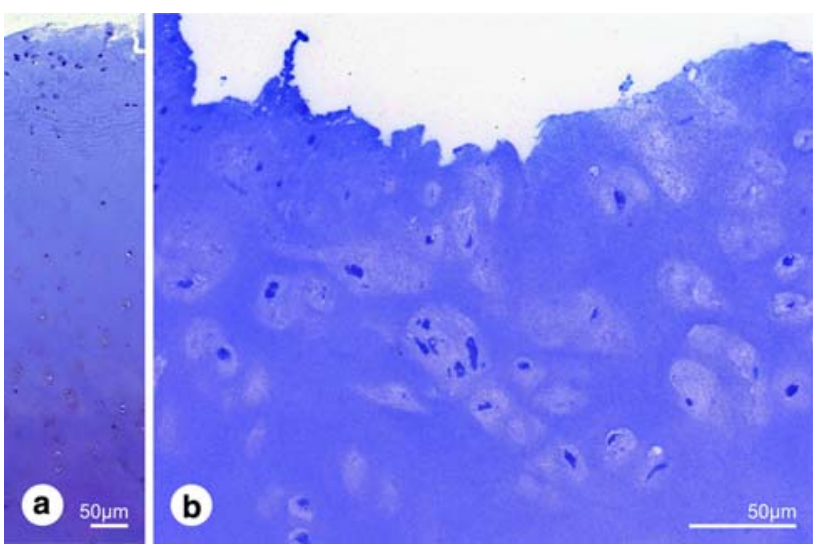

Fig. 2 Light micrographs of Richardson-stained semithin sections of degenerative cartilage. a Note loss of stratification as well as roughness and unevenness of articular surface. b Note damage to articular surface. Spindle-shaped chondrocytes, typical of the tangential zone, are almost completely missing. Articular surface and chondrones are damaged. The cytoplasm of chondrocytes contains cell debris and large vacuoles

remnants of the tangential zone were still present. As in healthy dogs, signal was absent from the pericellular matrix (Fig. 6, inset).

All negative control samples were devoid of immunolabeling (Figs. 7, 9).

\section{Tetrazolium formazan reaction}

Enzyme histochemistry and cytochemistry provided a highly specific and conspicuous signal especially when using NBT chloride as a substrate. As tissue penetration is subject to limitations, observations were made in peripheral
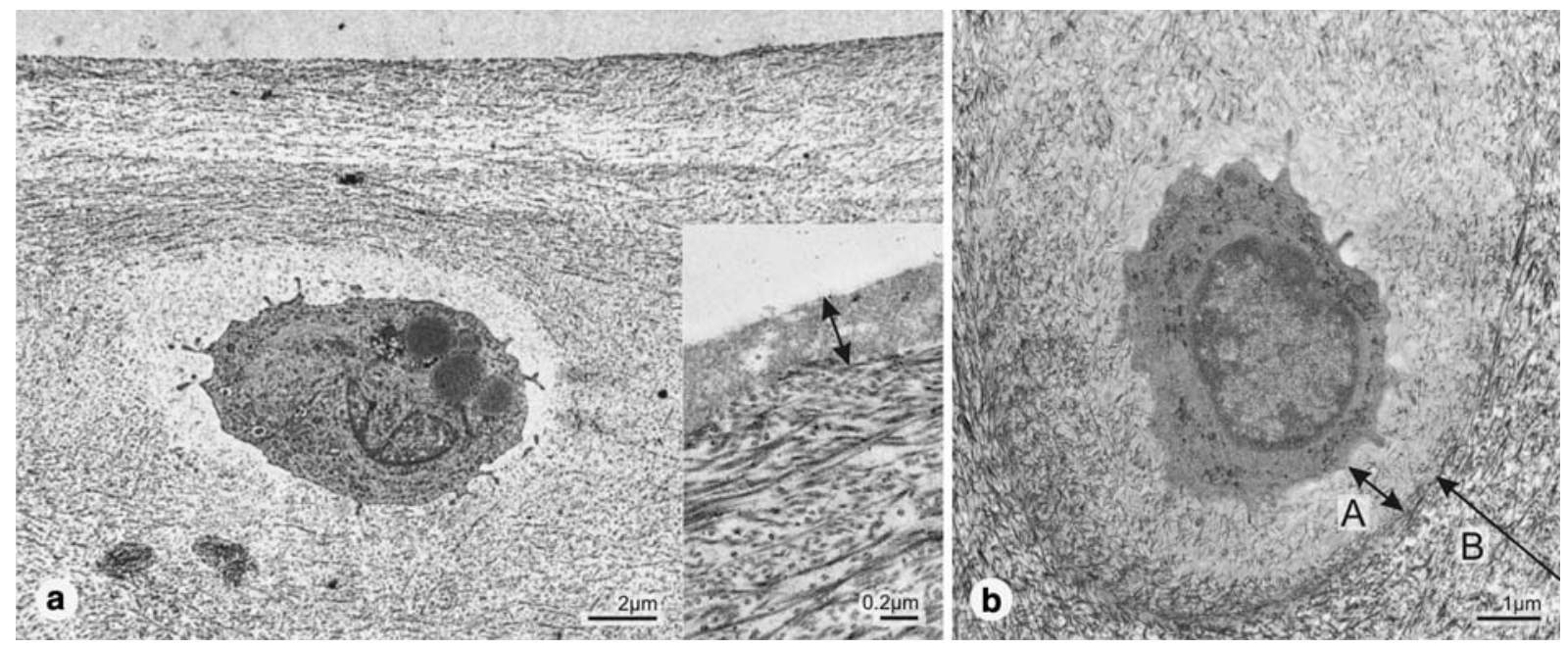

Fig. 3 Electron micrographs of healthy cartilage. a A dense superficial network of collagen fibers running in parallel with the articular surface is present. Chondrocytes contain numerous organelles and vesicles. Inset An amorphous layer (double arrow) extends at the sur- face. Underneath, densely packed collagen fibers run in parallel with the articular surface. b Territorial $(A)$ and interterritorial $(B)$ zones of extracellular matrix are clearly demarcated. Note the large nucleus and abundance of organelles in the chondrocyte 
Fig. 4 Electron micrograph of degenerative cartilage. The amorphous layer is missing, and the articular surface is uneven. Collagen fibers are loosely packed and arranged at random. Note amorphous foci in the extracellular matrix (arrows). (A) Territorial extracellular matrix

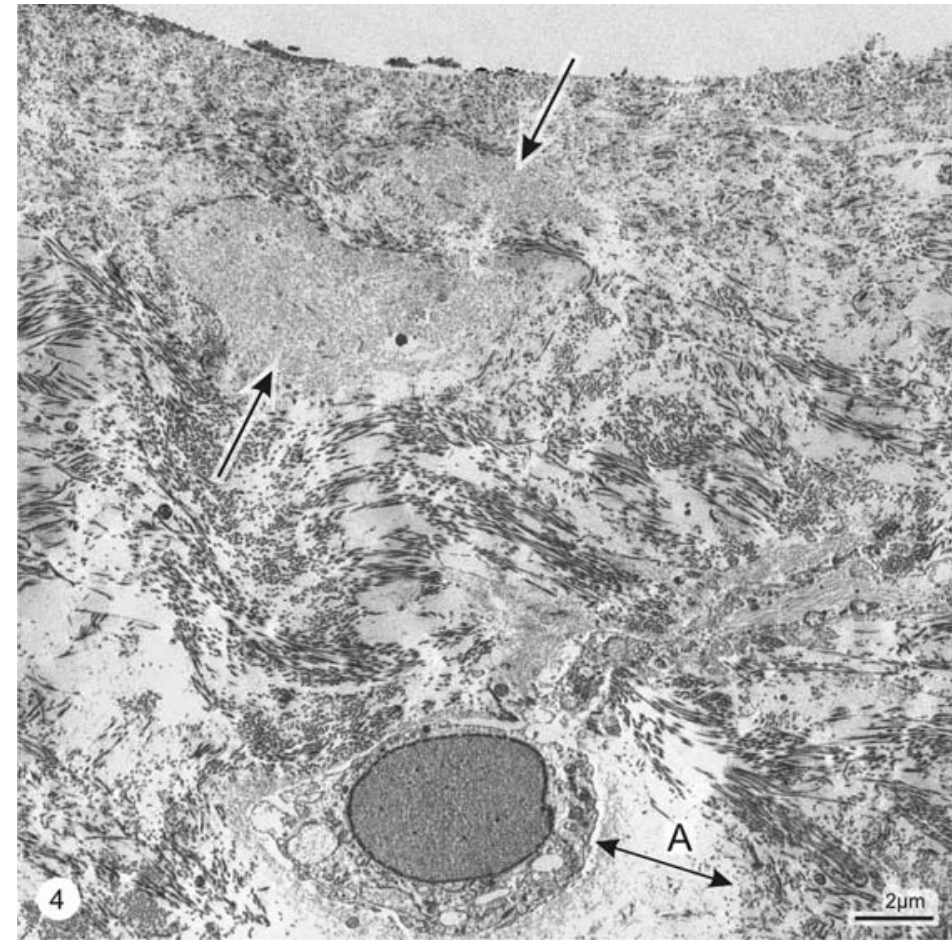

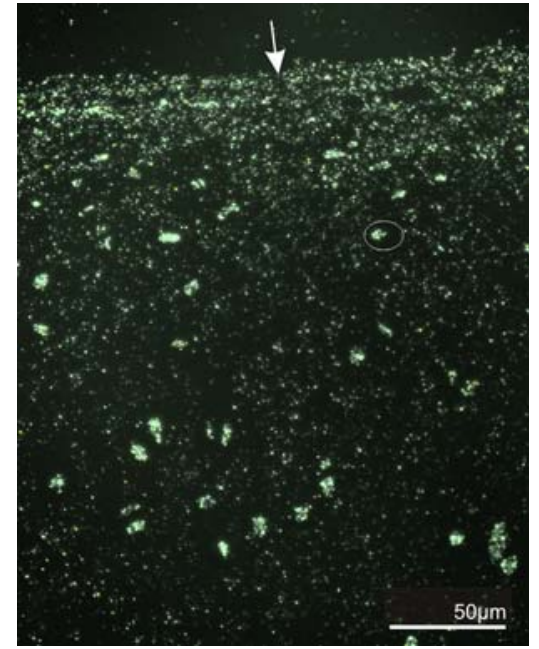

Fig. 5 Epipolarization micrograph of silver-enhanced immunogoldlabeling of healthy cartilage with anti-LDH. Chondrocytes in all three zones are strongly immunopositive, with the strongest cellular signal being noted in the radial zone. The pericellular extracellular matrix is devoid of labeling (encircled). A decrease in extracellular labeling intensity from tangential to radial zones is conspicuous. Signal in the amorphous layer and in most superficial collagen fibers is faint. (Arrow) Cartilage surface

regions of tissue samples. Osmication following enzyme histochemistry did not affect specificity when exposure to $\mathrm{OsO}_{4}$ was limited to $1 \mathrm{~h}$ but yielded false positive results when incubation was extended to $2 \mathrm{~h}$.

Negative controls showed no or only a faint background staining underneath the cell membrane (Figs. 12, 14).

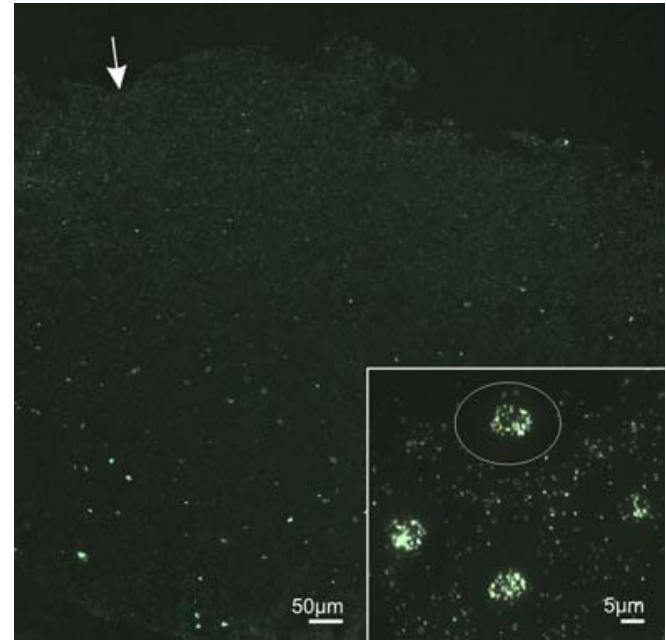

Fig. 6 Epipolarization micrograph of silver-enhanced immunogoldlabeling of degenerative cartilage with anti-LDH. Labeling of chondrocytes is faint. Unlike in healthy cartilage, labeling intensity in the extracellular matrix does not increase from deeper to superficial layers. (Arrow) Cartilage surface. Inset Signal is absent from the pericellular zone of the extracellular matrix (encircled)

In healthy cartilage, nuclei of chondrocytes were free of reaction product, whereas the cytoplasm exhibited an intense staining strongest beneath the cell membrane (Figs. 10, 13). With regard to the ECM, signal decreased from the tangential to radial zones, with a narrow layer at the articular surface remaining devoid of reaction product (Fig. 10). Furthermore, a concentric gradient was observed within the territorial matrix, where the signal 


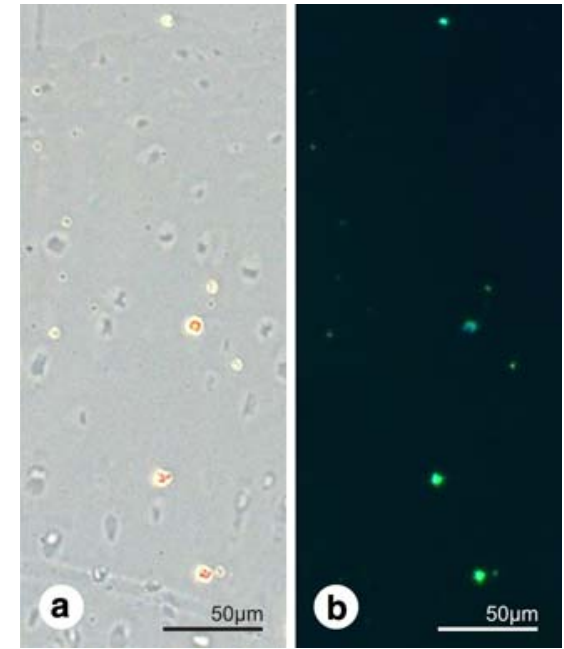

Fig. 7 Negative control for immunohistochemistry of degenerative cartilage. A goat anti-human choline acetyltransferase antibody was used as an irrelevant primary antibody for silver-enhanced immunogold-labeling. Note complete absence of signal except for a few solitary unspecific precipitates. a phase contrast, $\mathbf{b}$ epipolarization micrograph

decreasing from the cell border to the periphery (Fig. 10, inset).

In some respects, cellular staining in degenerative cartilage was similar to the signal observed in healthy animals. Thus, ECM of degenerative cartilage exhibited the concen- tric gradient in pericellular matrix as well, most prominently in the radial zone (Fig. 11, inset). The gradient from superficial to deeper layers, however, was absent in diseased animals (Fig. 11).

\section{Synovial fluid}

Synovial fluid (SF) was obtained from eight out of nine dogs with DJD, as aspiration of fluid failed in one dog. Volumes collected ranged from 0.5 to $1.9 \mathrm{ml}$. Results of laboratory analyses are summarized in Table 3 .

Cytology was performed in seven cases. Mainly mononuclear cells (macrophages and synovial lining cells) with a moderately to markedly enlarged cytoplasm in combination with cytoplasmic vacuolization were observed. Polynucleated giant cells were present in one dog. Lymphocytes and polymorphonuclear granulocytes were within the normal range. Occasionally, a few osteoclasts (5 dogs), blood cells (4 dogs), and plasma cells ( $1 \mathrm{dog})$ were found.

\section{Blood}

Blood parameters from all control animals were within normal range except for a slight neutrophilia with left shift in one dog suffering from a protein-losing enteropathy (as based on gastro-intestinal endoscopic findings).

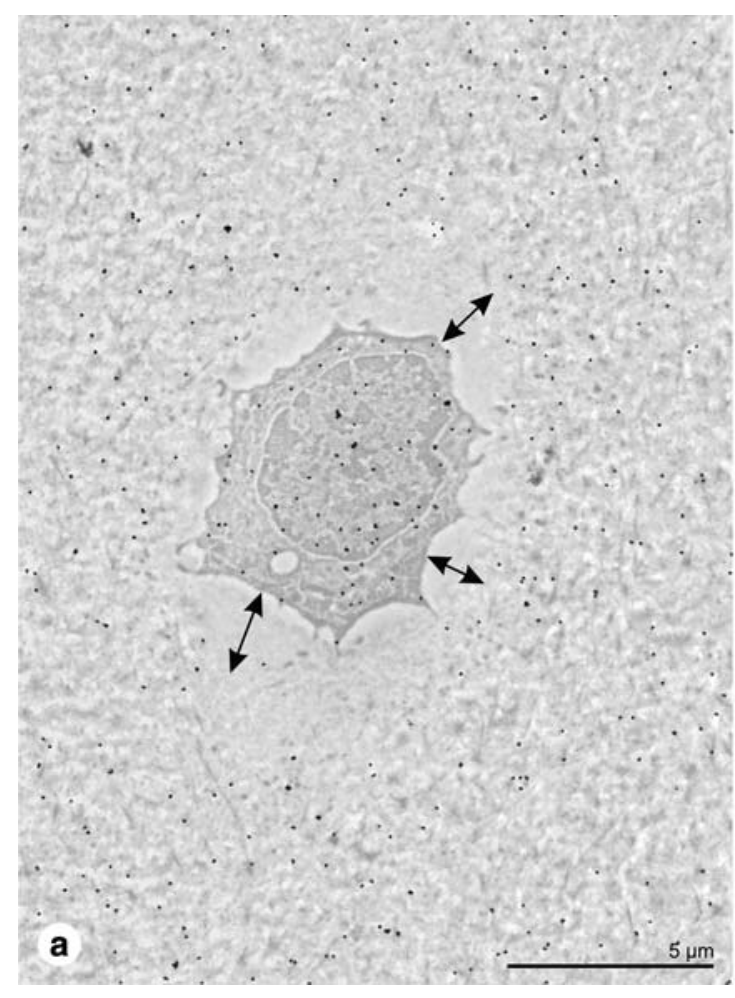

Fig. 8 Immunogold-labeling of healthy cartilage with anti-LDH. a Chondrocyte and interterritorial matrix are strongly immunopositive. The territorial extracellular matrix, however, is devoid of signal (double

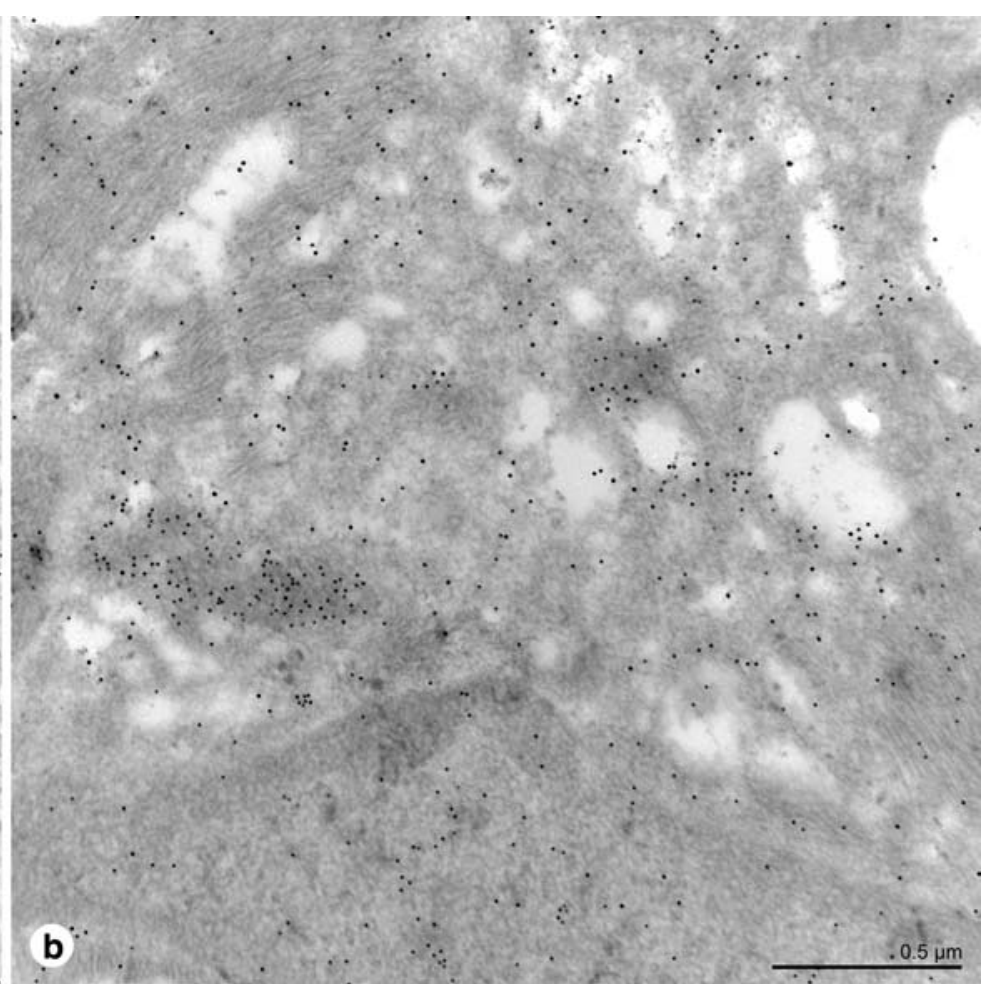

arrows) in this stained ultrathin section. $\mathbf{b}$ The dense labeling of the cytoplasm reveals regional differences in the abundance of LDH. The nucleus is also moderately labeled in this double stained ultrathin section 
Fig. 9 Negative control for immunocytochemistry. A goat anti-human choline acetyltransferase antibody was used as an irrelevant primary antibody for immunogold-labeling. Note complete absence of any background labelling, unstained ultrathin section

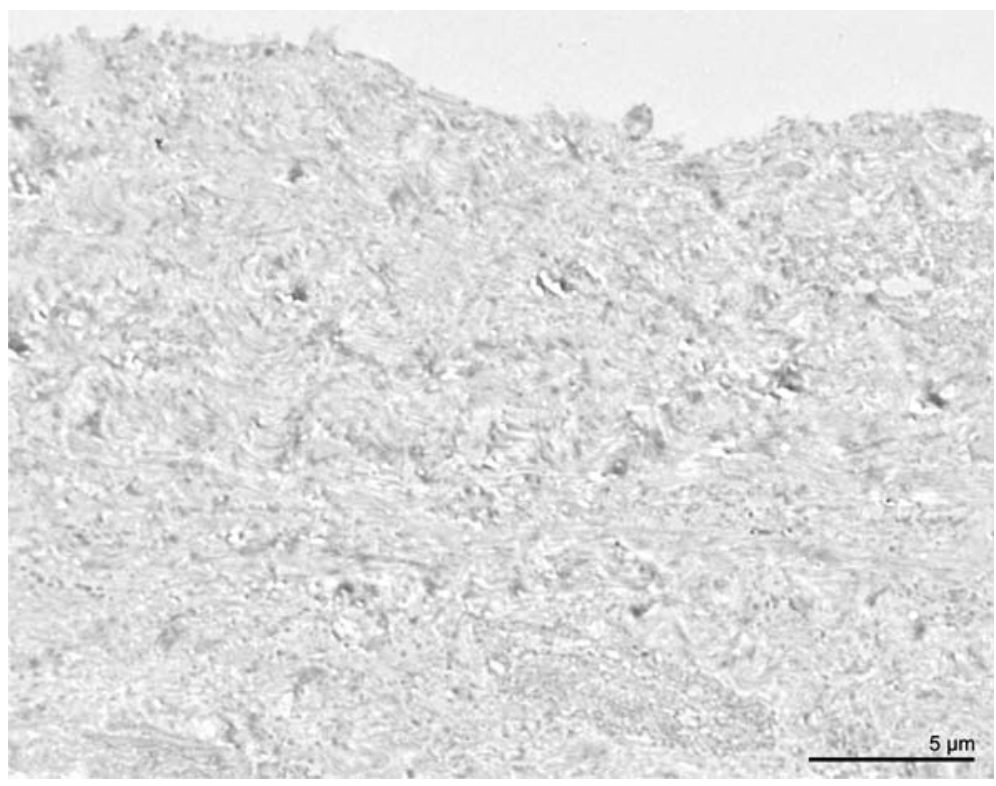

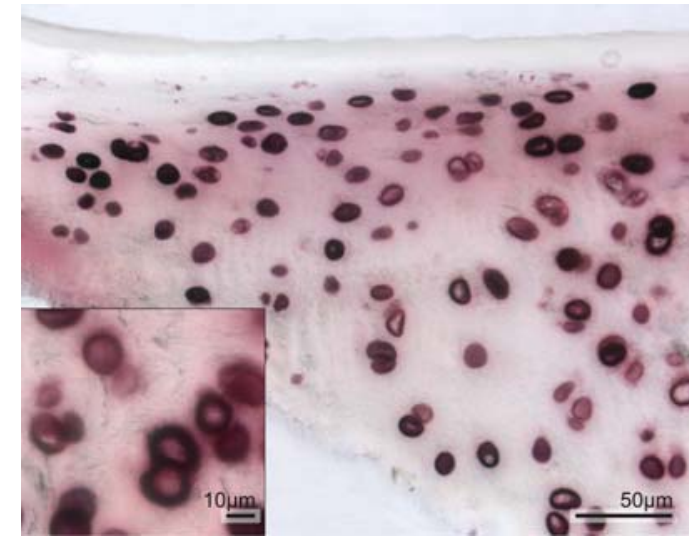

Fig. 10 Enzyme histochemical demonstration of LDH in healthy cartilage. The tetrazolium formazan reaction reveals an obvious decrease in LDH-concentration from tangential to radial zones. Furthermore, enzyme activity is completely absent from the most superficial layers at the articular surface. Inset: The territorial matrix displays a concentric gradient with decreasing enzyme activity from the cell border to the periphery

Results of blood sample analyses from all the $\operatorname{dog} s$ suffering from DJD are summarized in Table 3.

\section{Discussion}

Chronic joint diseases are commonly characterized as being either inflammatory or degenerative. Whereas, the diagnosis of arthritis can fall back upon a number of reliable indicators present in synovial fluid (SF), convenient markers for degenerative joint diseases (DJD) are still lacking in the dog. Although a number of indicators of articular damage, such as collagen fragments, aggrecan fragments, metalloproteinases, and tissue inhibitor of metalloproteinase, have

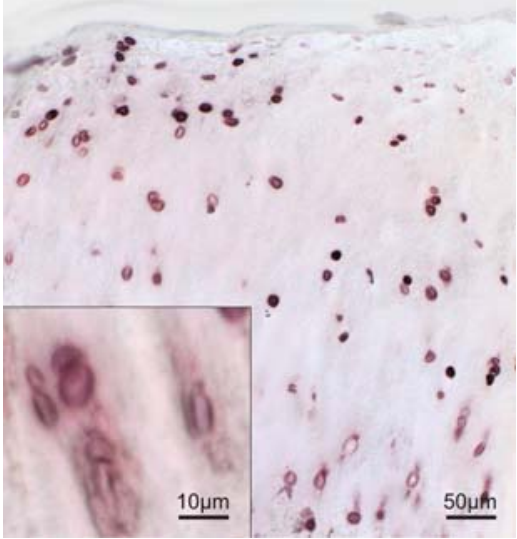

Fig. 11 Enzyme histochemical demonstration of LDH in degenerative cartilage. Unlike in healthy cartilage, no vertical gradient in enzyme activity is discernible. Inset The concentric gradient in the pericellular extracellular matrix is similar to its counterpart in healthy cartilage

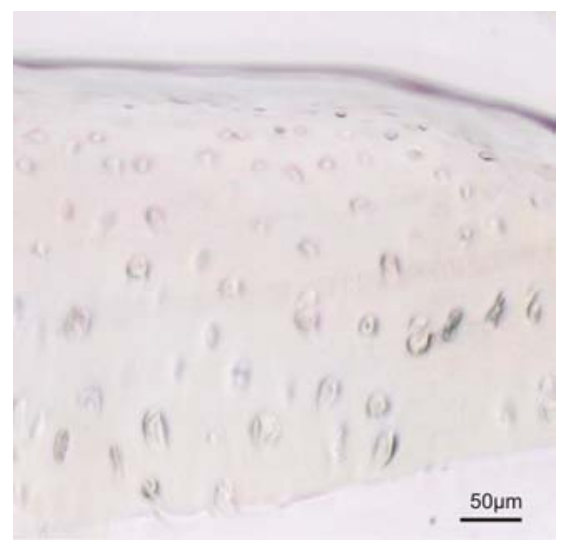

Fig. 12 Negative control for enzyme histochemistry. Light micrograph of healthy cartilage after incubation in the absence of substrate. Note complete absence of reaction product 
Fig. 13 Enzyme cytochemical demonstration of LDH in healthy cartilage. Conspicuous intracellular formazan deposits are present in the cytoplasm but are absent from vacuoles

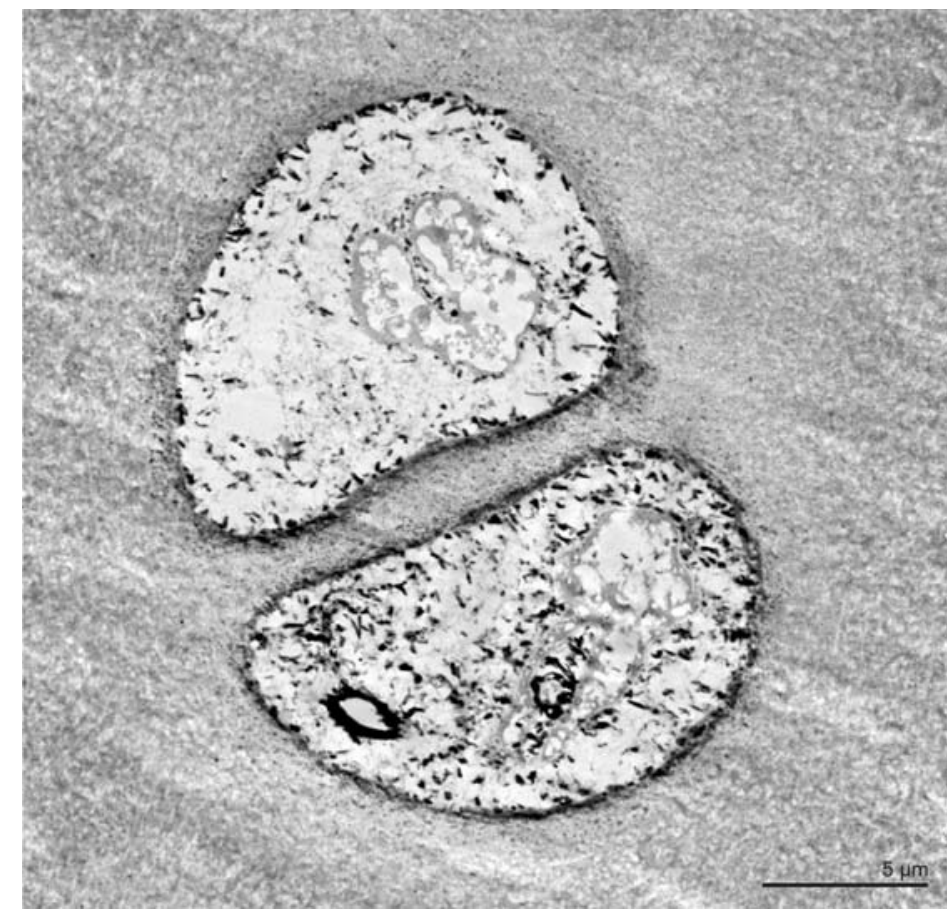

horses and humans unanimously demonstrated an overall increase in synovial LDH activity in conjunction with a number of inflammatory and non-inflammatory joint diseases, such as infectious arthritis, rheumatoid arthritis, gout, and osteochondrosis dissecans (Lindy et al. 1971; Messieh 1996; Pejovic et al. 1992; Rejno 1976; Yancik et al. 1987). As for the dog, it has been shown recently that LDH activity in SF is likely to correlate with the extent of degenerative lesions, thus making LDH a potentially useful and specific marker for DJD (Hurter et al. 2005; Schmöckel et al. 2001).

The present study was designed to corroborate the correlation between increased LDH activities in SF and DJD in dogs and determine where the enzyme found in SF originates. Analyses of blood and SF samples were performed in order to eliminate dogs with immune mediated or acute inflammatory joint diseases from the study. Thus, only dogs with arthroscopically and microscopically diagnosed DJD but with blood and synovial leucocyte and neutrophil counts within normal range were included. Taking into account the diluting effect owing to the large sample volume in dog 4, the activity of LDH in SF was increased in six out of eight cases of DJD, thus supporting the contention of LDH as being a valuable indicator of DJD. Our results also confirm that LDH activity in SF from degenerative joints does not correlate with synovial cell counts (Hurter et al. 2005; Pejovic et al. 1992; Schmöckel et al. 2001). Thus, the enzyme cannot originate from blood cells.

The synovial membrane is another possible source of LDH that must be considered. However, permeability of synovial membranes is limited to molecules up to $100 \mathrm{kDa}$

early reports implied that DJD might not alter enzy activities in SF (Cohen 1964). However, later studies in 
Table 3 Results of SF and blood

\begin{tabular}{|c|c|c|c|c|c|c|c|c|c|c|c|}
\hline \multicolumn{10}{|c|}{ Synovial fluid } & \multicolumn{2}{|c|}{ Blood Plasma } \\
\hline Patient & Color & Turbidity & Viscosity & $\begin{array}{l}\text { Protein } \\
(\mathrm{g} / \mathrm{l})\end{array}$ & $\begin{array}{l}\text { Cells } \\
\left(\times 10^{9} / 1\right)\end{array}$ & $\begin{array}{l}\text { Volume } \\
(\mathrm{ml})\end{array}$ & $\begin{array}{l}\text { ASAT } \\
\text { (IU/l) }\end{array}$ & $\begin{array}{l}\mathrm{AP} \\
(\mathrm{IU} / \mathrm{l})\end{array}$ & $\begin{array}{l}\text { LDH } \\
\text { (IU/l) }\end{array}$ & $\begin{array}{l}\text { ASAT } \\
\text { (IU/l) }\end{array}$ & $\begin{array}{l}\text { LDH } \\
\text { (IU/l) }\end{array}$ \\
\hline $\begin{array}{r}\text { Normal } \\
\text { range }\end{array}$ & $\begin{array}{l}\text { None to light } \\
\text { yellow }\end{array}$ & Clear & $+/++$ & $20-25$ & $0-3$ & -1 & $10-76$ & $14-126$ & $\begin{array}{l}\text { Healthy: } 61 \pm 9 \\
\text { DJD: } 120 \pm 9\end{array}$ & $20-73$ & $66-319$ \\
\hline 1 & Yellow & Turbid & + & 29 & 0.9 & & 50 & 46 & 116 & 87 & 187 \\
\hline 2 & Yellow & Clear & ++ & 30 & 0.7 & & 18 & 34 & 64 & 29 & 246 \\
\hline 3 & Yellow to reddish & Clear & ++ & 20 & 0.7 & 0.5 & 36 & & 238 & 34 & 156 \\
\hline 4 & Light yellow & Clear & ++ & 32 & 0.8 & 1.9 & 26 & 40 & 64 & 23 & 79 \\
\hline 5 & Red & & & 26 & 2.5 & 0.5 & & & 346 & 53 & 868 \\
\hline 6 & Light yellow & Turbid & ++ & 26 & 0.8 & & & & 110 & 30 & 174 \\
\hline 7 & Yellow & Light turbid & + & 24 & 1.3 & 1.5 & 24 & 46 & 181 & 20 & 660 \\
\hline 8 & Yellow & Clear & & 13 & 0.9 & 1 & 19 & 58 & 87 & 39 & 310 \\
\hline
\end{tabular}

(Lipowitz 1985; Lipowitz and Newton 1985; Maroudas and Schneiderman 1987). Molecular weight of LDH is $140 \mathrm{kD}$, and in addition, this enzyme carries a net negative charge. Bearing in mind that analysis of SF speaks against an increase in permeability, the possibility that LDH might originate from the synovial membrane can be ruled out.

The presence of LDH in joint cartilage has been documented in various species including the dog (Altman 1981; Dunham et al. 1986; Pelletier et al. 1985; Schiefke et al. 1998; Tushan et al. 1969; Weseloh and Fiesselmann 1975). In tibial plateau cartilage of normal dogs, LDH was reported to be homogeneously spread in superficial, upper transitional, and radial zones, with higher values noticed in the deeper transitional zone (Dunham et al. 1986). The present study now provides additional information as to the distribution of LDH in articular cartilage. Enzyme cytochemistry and immunolabeling clearly demonstrated high levels of cytosolic LDH activity in viable chondrocytes of both healthy dogs and dogs with DJD. Furthermore, some labeling was also seen in nuclei as shown by electron microscopy. LDH is known to be a soluble glycolytic enzyme. However, its intracellular distribution is not restricted to the cytoplasm. Rather, early reports on the presence of LDH in the nucleus date back to 1965 (Siebert and Humphrey 1965; Siebert et al. 1966). More specifically, LDH-5 has been located to the nucleus, and evidence has been provided that it may function in the regulation of gene transcription or DNA replication. It is considered to be a single-stranded DNA-binding protein that stimulates the activity of DNA poymerase $\alpha$ in vitro (Cattaneo et al. 1985; Grosse et al. 1986; Zhong and Howard 1990).

In addition, substantial amounts of LDH were present in the cartilage matrix. The enzyme has been suspected to be contained in matrix vesicles (Hosokawa et al. 1992, 1988; Maki et al. 2000; Ohashi-Takeuchi et al. 1990). In our material, such vesicles were commonly noticed by electron microscopy. However, neither enzyme cytochemistry nor immunolabeling were indicative of any $\mathrm{LDH}$ accumulation within vesicles.

In healthy dogs, a decrease in LDH activity in the ECM from superficial to deep cartilage layers was substantiated by both immunolabeling and enzyme cytochemistry, thus suggesting accumulation of LDH within the tangential zone as compared to the transitional and radial zones. We consider this to be a corollary of the higher metabolic activity in superficial cartilage layers (Dunham et al. 1986). Such a gradient, however, was absent in degenerative cartilage. The lack of a density gradient in degenerative joints was always associated with the erosion of the tangential layer as revealed by morphological analysis. Inversely, the gradient was still present in those areas in which the most superficial cartilage layer was preserved. Thus, an intact tangential zone, including a lamina splendens, obviously provides containment, and its absence predictably will allow leakage of LDH into SF. This contention is further supported by the observation that the exposed cartilage surface in degenerative joints was virtually devoid of LDH. Furthermore, homogeneous distribution of LDH in DJD obviously reflects differences between healthy and degenerative cartilage matrix with respect to permeability. This correlates with the observation of dissociated collagen fiber bundles and loss of fiber orientation in tangential and transitional zones, these characteristics being indicative of increased water content in the cartilaginous matrix (Adams and Billingham 1982; Roughley et al. 1992; Stockwell et al. 1983). Thus, whereas healthy cartilage is able to restrict the diffusion of molecules larger than albumin (Van Bree et al. 1994), differences in LDH distribution are leveled out in degenerative tissue due to increased permeability (Thonar et al. 1992). 
In summary, we suggest that cytosolic LDH is released from chondrocytes into the cartilage matrix. Whereas LDH is retained in healthy cartilage due to permeability limitations, it is released into SF in degenerative joints through abrasion as well as through unrestricted diffusion as a result of increased water content and degradation of collagen.

Acknowledgments The outstanding technical assistance of Mrs C. Furer and Mrs C. Hug is gratefully acknowledged. We are also indebted to the laboratory of Prof. Tschudi for blood and SF analysis and to Mr. S. König for his excellent photographic work.

\section{References}

Adams ME, Billingham ME (1982) Animal models of degenerative joint disease. Curr Top Pathol 71:265-297

Altman FP (1981) A metabolic dysfunction in early murine osteoarthritis. Ann Rheum Dis 40(3):303-306

Arsenault AL, Hunziker EB (1988) Electron microscopic analysis of mineral deposits in the calcifying epiphyseal growth plate. Calcif Tissue Int 42(2):119-126

Cattaneo A, Biocca S, Corvaja N, Calissano P (1985) Nuclear localization of a lactic dehydrogenase with single-stranded DNA-binding properties. Exp Cell Res 161(1):130-140

Chu Q, Lopez M, Hayashi K, Ionescu M, Billinghurst RC, Johnson KA, Poole AR, Markel MD (2002) Elevation of a collagenase generated type II collagen neoepitope and proteoglycan epitopes in synovial fluid following induction of joint instability in the dog. Osteoarthr Cartil 10(8):662-669

Cohen AS (1964) Lactic dehydrogenase (LDH) and transaminase (GOT) activity of synovial fluid and serum in rheumatic disease states, with a note on synovial fluid LDH isozymes. Arthritis Rheum 19:490-501

Dunham J, Shackleton DR, Bitensky L, Chayen J, Billingham ME, Muir IH (1986) Enzymic heterogeneity of normal canine articular cartilage. Cell Biochem Funct 4(1):43-46

Grosse F, Nasheuer HP, Scholtissek S, Schomburg U (1986) Lactate dehydrogenase and glyceraldehyde-phosphate dehydrogenase are single-stranded DNA-binding proteins that affect the DNA-polymerase-alpha-primase complex. Eur J Biochem 160(3):459-467

Hayashi K, Frank JD, Hao Z, Schamberger GM, Markel MD, Manley PA, Muir P (2003) Evaluation of ligament fibroblast viability in ruptured cranial cruciate ligament of dogs. Am J Vet Res 64(8):1010-1016

Hosokawa R, Ohashi-Takeuchi H, Yamada N, Uchida Y, Fujiwara S, Noguchi T (1992) Lactate dehydrogenase isoenzymes in matrix vesicles (review). Bone Miner 17(2):177-181

Hosokawa R, Uchida Y, Fujiwara S, Noguchi T (1988) Lactate dehydrogenase isoenzymes are present in matrix vesicles. J Biol Chem 263(21):10045-10047

Hurter K, Spreng D, Rytz U, Schawalder P, Ott-Knusel F, Schmökel H (2005) Measurements of C-reactive protein in serum and lactate dehydrogenase in serum and synovial fluid of patients with osteoarthritis. Vet J 169(2):281-285

Johnston SA (1997) Osteoarthritis: joint anatomy, physiology and pathobiology. 27:699-723

Lindy S, Turto H, Uitto J, Vainio K (1971) Origin of synovial fluid lactate dehydrogenase in rheumatoid arthritis. Clin Chim Acta 35(2):377-382

Lipowitz AJ (1985) Synovial Fluid. In: Newton CD, Nunamaker DM (eds.) Textbook of small animal orthopaedics, International Veterinary Information Service, Ithaca, Chapter 86
Lipowitz AJ, Newton CD (1985) Degenerative Joint Disease and Traumatic Arthritis. In: Newton CD, Nunamaker DM (eds.) Textbook of small animal orthopaedics, International Veterinary Information Service, Ithaca, Chapter 87

Lohmander LS (1994) Articular cartilage and osteoarthrosis. The role of molecular markers to monitor breakdown, repair and disease. J Anat 184(Pt 3):477-492

Lohmander LS, Dahlberg L, Eyre D, Lark M, Thonar EJ, Ryd L (1998) Longitudinal and cross-sectional variability in markers of joint metabolism in patients with knee pain and articular cartilage abnormalities. Osteoarthr Cartil 6(5):351-361

Maki K, Hayashi S, Nishioka T, Kimura M, Noguch T (2000) A new type of matrix vesicles is found in fetal bovine tracheal cartilage. Connect Tissue Res 41(2):109-115

Maroudas A, Schneiderman R (1987) "Free" and "exchangeable" or "trapped" and "non-exchangeable" water in cartilage. J Orthop Res 5(1):133-138

Messieh M (1996) Levels of lactate dehydrogenase in osteoarthritic and failed total knee joints. J Arthroplasty 11(3):354-355

Ohashi-Takeuchi H, Yamada N, Hosokawa R, Noguchi T (1990) Vesicles with lactate dehydrogenase and without alkaline phosphatase present in the resting zone of epiphyseal cartilage. Biochem J 266(1):309-312

Pejovic M, Stankovic A, Mitrovic DR (1992) Lactate dehydrogenase activity and its isoenzymes in serum and synovial fluid of patients with rheumatoid arthritis and osteoarthritis. J Rheumatol 19(4):529-533

Pelletier JP, Martel-Pelletier J, Ghandur-Mnaymneh L, Howell DS, Woessner JF Jr (1985) Role of synovial membrane inflammation in cartilage matrix breakdown in the Pond-Nuki dog model of osteoarthritis. Arthritis Rheum 28(5):554-261

Rejno S (1976) LDH and LDH isoenzymes of synovial fluid in the horse. Acta Vet Scand 17(2):178-189

Roughley PJ, Nguyen Q, Mort JS (1992) The role of proteinases and oxygen radicals in the degradation of human articular cartilage. pp. $305-318$

Schiefke I, Weiss J, Keller F, Leutert G (1998) Morphological and histochemical ageing changes in patellar articular cartilage of the rat. Anat Anz 180(6):495-500

Schmöckel H, Messmer M, Lutz H (2001) Messung der Aktivitäten der alkalischen Phosphatase, Aspartataminotransferase und Laktatdehydrogenase in der Synovialflüssigkeit gesunder und veränderter Gelenke beim Hund. Wiener Tierärztliche Monatsschrift (5):118-121

Siebert G, Humphrey GB (1965) Enzymology of the nucleus. Adv Enzymol Relat Areas Mol Biol 27:239-288

Siebert G, Villalobos J Jr, Ro TS, Steele WJ, Lindenmayer G, Adams H, Busch H (1966) Enzymatic studies on isolated nucleoli of rat liver. J Biol Chem 241(1):71-78

Slater RR Jr, Bayliss MT, Lachiewicz PF, Visco DM, Caterson B (1995) Monoclonal antibodies that detect biochemical markers of arthritis in humans. Arthritis Rheum 38(5):655-659

Stockwell RA, Billingham ME, Muir H (1983) Ultrastructural changes in articular cartilage after experimental section of the anterior cruciate ligament of the dog knee. J Anat 136(2):425-439

Thonar EJ-MA, Manicourt DH, Williams JM, Fukuda K, Campion GV, Sweet BME, Lenz ME, Schnitzer TJ, Kuettner KE (1992) Serum Keratan Sulfate: a measure of cartilage proteoglycan metabolism. In: Kuettner KE, Schleyerbach R, Peyron JG, Hascall VC (eds) Articular Cartilage and Osteoarthritis, Raven Press New York, pp 429-446

Tushan F, Rodnan GP, Altman M, Robin ED (1969) Anaerobic glycolysis and lactate dehydrogenase (LDH) isoenzymes in articular cartilage. J Lab Clin Med 73(4):649-656

Van Noorden CJ (1984) Histochemistry and cytochemistry of glucose-6-phosphate dehydrogenase. Prog Histochem Cytochem 15(4):1-85 
Van Bree H, Justus C, Quirke JF (1994) Preliminary observations on the effects of meloxicam in a new model for acute intra-articular inflammation in dogs. Vet Res Commun 18(3):217-224

Weseloh G, Fiesselmann A (1975) [Distribution of the isoenzym lactatdehydrogenase in human cartilage (author's transl)]. Arch Orthop Unfallchir 83(3):345-351
Yancik SA, McIlwraith CW, Wagner AE, Trotter GW (1987) Evaluation of creatine kinase and lactate dehydrogenase activities in clinically normal and abnormal equine joints. Am J Vet Res 48(3):463-466

Zhong XH, Howard BD (1990) Phosphotyrosine-containing lactate dehydrogenase is restricted to the nuclei of PC12 pheochromocytoma cells. Mol Cell Biol 10(2):770-776 